\title{
ENHANCED PERFORMANCE OF NATURAL DYE SENSITISED SOLAR CELLS FABRICATED USING RUTILE TIO 2 NANORODS
} \author{
Akila.Y ${ }^{1 *}$, Muthukumarasamy.N ${ }^{1}$, Agilan.S ${ }^{1}$, Tapas K Mallick ${ }^{2}$, S. Senthilarasu ${ }^{2}$, Dhayalan \\ Velauthapillai ${ }^{3}$ \\ ${ }^{1}$ Department of Physics, Coimbatore Institute of Technology, Coimbatore, Tamilnadu, India \\ E.mail: akilayuva@gmail.com,vishnukutty2002@yahoo.co.in. \\ ${ }^{2}$ Environment and Sustainability Institute, University of Exeter, Penryn, Cornwall TR10 9FE \\ United Kingdom \\ ${ }^{3}$ Faculty of Engineering and Business Administration, Bergen University College, Bergen, \\ Norway
}

\begin{abstract}
Due to the lower cost, natural dye molecules are good alternatives for the ruthenium based sensitizers in the dye-sensitized solar cells. In this article, we have reported the natural sensitizer based dye-sensitized solar cells fabricated using $\mathrm{TiO}_{2}$ nanorods. Rutile phase $\mathrm{TiO}_{2}$ nanorods have been synthesized by template free hydrothermal method which results in $\mathrm{TiO}_{2}$ nanorods in the form of acropora corals. These $\mathrm{TiO}_{2}$ nanorods have been sensitized by flowers of Sesbania grandiflora, leaves of Camellia sinensis and roots of Rubia tinctorum. The maximum conversion efficiency of $1.53 \%$ has been obtained for $\mathrm{TiO}_{2}$ nanorods based solar cells sensitized with the leaves of Camellia sinensis. The flowers of Sesbania grandiflora and roots of Rubia tinctorum sensitized $\mathrm{TiO}_{2}$ nanorods based solar cells exhibited an efficiency of $0.65 \%$ and $1.28 \%$ respectively.
\end{abstract}

Keywords: Semiconductors;Thin films; Nanostructures;Chemical synthesis.

\section{Introduction}

Renewable energy is one of the key technologies available to meet the world's energy needs. Solar energy provides clean abundant energy and is therefore an excellent candidate for future environmental friendly energy source. The aim of solar cell research is to increase the solar energy conversion efficiency at low cost to provide a cost-effective sustainable energy source. To meet the demand of reducing material and purification costs, thin film solar cells have been developed. 
Dye sensitized solar cells (DSSC) as a promising candidate has improved the development lines of renewable energy. The DSSC is a device for the conversion of visible light into electricity, based on the sensitization of wide band gap semiconductors [1]. DSSC is composed of nanocrystalline semiconductor photo anode - absorbed dye, a counter electrode and an electrolyte containing iodide and tri iodide ions. The working principle of DSSC is shown in Fig.1

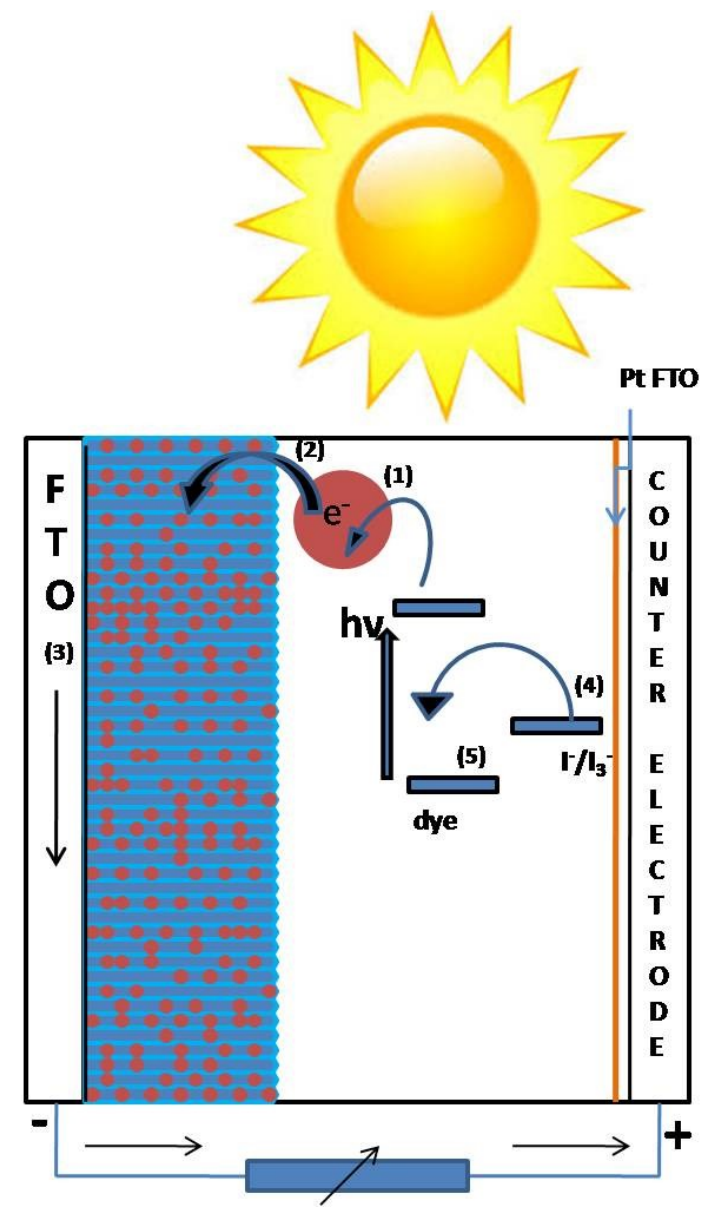

Fig.1 Working principle of DSSC

From Fig.1 the three major processes in DSSCs are shown:

1. Light harvesting and generation of the dye excited states(Step (1) - Fig.1)

2. The electron injection and transportation (Step $(2,3)$ - Fig.1)

3. Reduction of the excited dye(Step $(4,5)$ - Fig.1)

These processes occur at the dye/ $/ \mathrm{TiO}_{2}$, dye/electrolyte and $\mathrm{TiO}_{2} /$ electrolyte interfaces. 


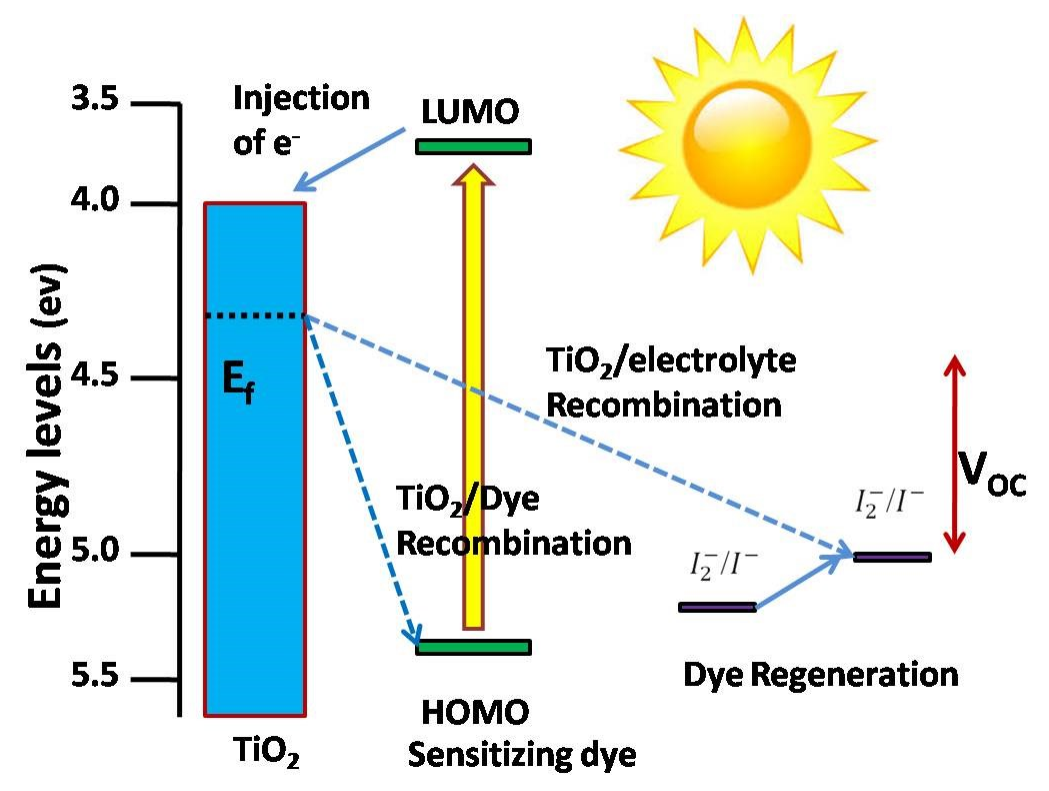

Fig.2 Energy band diagram of the electron injection process in DSSC

Figure 2 the energy band diagram illustrate the electron injection process: (a) Electron in the dye is excited to the acceptor energy level (b) the acceptor energy level of the dye transfers the electron to the conduction band of the semi conductor (c) dye regeneration in the redox electrolyte (d) the redox electrolyte regains the electron from the counter electrode. The operation of DSSC is initiated when sunlight falls on photo anode striking the dye on the anode. Photons striking the dye will be absorbed to create an excited state of the dye, from which the electron is injected directly into the conduction band of the $\mathrm{TiO}_{2}$. The absorption spectrum of the dye and the anchorage of the dye to the surface of $\mathrm{TiO}_{2}$ are important parameters determining the efficiency of the cell [2]. To be effective, it requires the highest occupied molecular orbital (HOMO) of the dye to reside in the band gap of the semiconductor and its lowest unoccupied molecular orbital (LUMO) to lie within the conduction band of the semiconductor. The performance of the cell mainly depends on the dye used as sensitizer [3].

In DSSC, the dye sensitizer carries out the light harvesting function and is therefore crucial in determining the overall cell efficiency. Dye is a colorant derived from plants, animals or minerals. The best photovoltaic performance by means of efficiency and stability has been achieved by ruthenium $(\mathrm{Ru})$ complexes. Ruthenium complexes are not cheap and also the synthesis is laborious. As an alternative, natural dye sensitized solar cell stands with the advantages of easy availability, low fabrication cost, elegant and simple preparation method. A 
plant pigment is any type of colored substance produced by a plant. In general, any chemical compound which absorbs visible radiation between about $380 \mathrm{~nm}$ (violet) and $760 \mathrm{~nm}$ (ruby-red) is considered a pigment. Color produced by the pigments is due to a molecule-specific structure known as chromophore. This structure captures the energy and results in the excitation of electron from an orbital to a higher orbital.

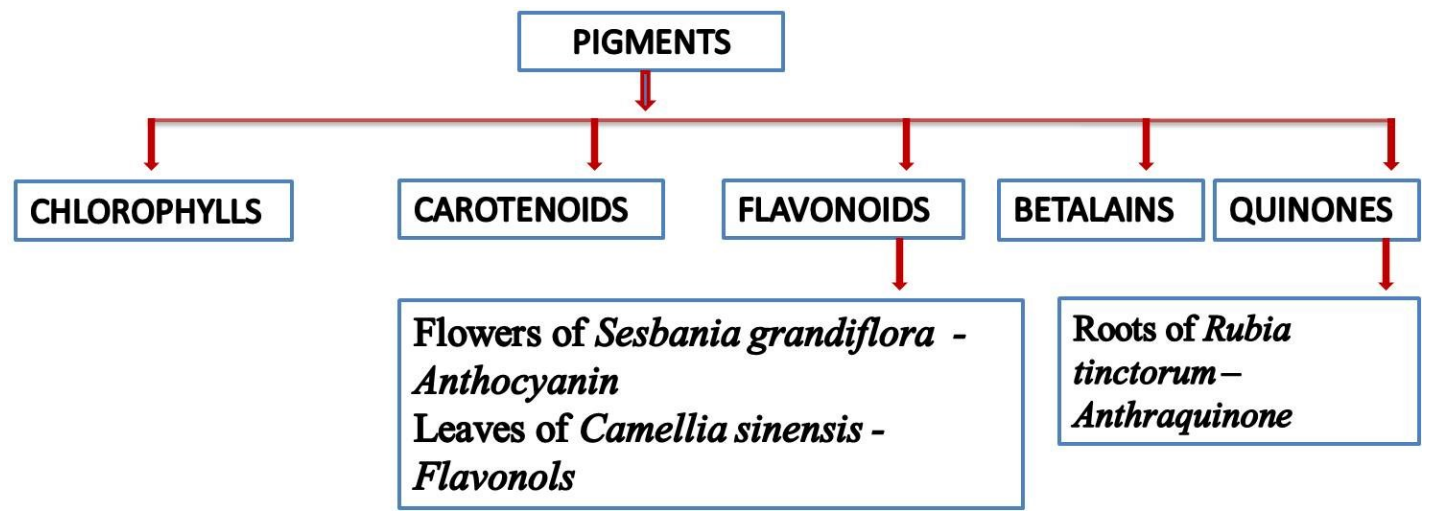

Fig.3 Classification of natural plant pigments

Fig.3 summarizes the main classification of plant pigments. The natural dye extracts from the flowers of Sesbania grandiflora and leaves of Camellia sinensis belong to the flavonoids group. Quinone derivatives are biologically active compounds in plants. The roots of Rubia tinctorum fall under quinone derivative. Dye structure helps in better anchoring to the surface of $\mathrm{TiO}_{2}$ and drives the electron into the conduction band of the $\mathrm{TiO}_{2}$. Conversely, dye structure can help to reduce the recombination process at $\mathrm{TiO}_{2} /$ dye and $\mathrm{TiO}_{2}$ /electrolyte. Therefore tuning dye sensitizer light absorbing properties and control of the aforementioned electron transfer processes through structural design of the dye sensitizer is an important avenue through which optimization of DSSC efficiency should be pursued.

Table 1 Efficiency of natural dye sensitized $\mathrm{TiO}_{2}$ based DSSC

\begin{tabular}{|c|c|c|c|}
\hline S.No. & Natural dye extract & Efficiency & Reference \\
\hline 1. & Undaria pinnatifida & $4 \%$ & {$[4]$} \\
\hline 2. & Chlorophyll a and b & $2 \%$ & {$[5]$} \\
\hline 3. & Spinacea oleracea & $4 \%$ & {$[6]$} \\
\hline 4. & Opuntia & $2.06 \%$ & {$[7]$} \\
\hline
\end{tabular}


Table 1 shows the photovoltaic conversion efficiency of $\mathrm{TiO}_{2}$ based DSSCs which have used natural dyes extracted from various plants. The efficiency shown in table 1 depicts the potency of natural dye to perform as a photo sensitizer which could be improved by better utilization of the dye.

Fast electron transfer process in the DSSCs could be improved by optimizing the $\mathrm{TiO}_{2}$ thin film. In search of efficient design of thin films, the highly oriented $\mathrm{TiO}_{2}$ nanorods promote the electron transfer by creating independent pathways. The etched surface of $\mathrm{TiO}_{2}$ nanorods provides a large surface area for dye loading and reduces the electron loss during the transfer of photo generated electrons through the nanostructures. The four main preparation methods used in the synthesis of $\mathrm{TiO}_{2}$ nanorods include hydrothermal method, sol-gel method, vapor deposition method and electro-spinning method. For the synthesis of nanocrystalline pure $\mathrm{TiO}_{2}$ with controlled crystalinity, hydrothermal method provides an effective reaction environment [8].

The performance of the film shall be improved by increasing the surface to volume ratio of the film and also by increasing the thickness of the film by introducing a surfactant as a primer. This could be obtained by using silane as a surfactant which can support to improve the surface coverage of the film. Silanes are widely used to improve the adhesion of a broad range of sealants and adhesives to inorganic substrates, such as metals, glass and stone. Alkoxysilanes have, therefore, broad utility in formulating primers and coatings for a variety of metallic and siliceous substrates. Silanization is based on the adsorption, self assembly and covalent binding of silane molecules onto surfaces, resulting in a densely packed self assembled monolayer (SAM).

In the present work, FTO substrates were pretreated with triethoxy ethyl silane as a primer and rutile $\mathrm{TiO}_{2}$ nanorods were synthesized on the substrates by hydrothermal method. These $\mathrm{TiO}_{2}$ nanorods were observed to have got arranged like the flower bouquet and they were sensitized using natural dye extracted from flowers of Sesbania grandiflora, leaves of Camellia sinensis and roots of Rubia tinctorum. The natural dye sensitized $\mathrm{TiO}_{2}$ electrodes have been used to fabricate solar cells and the characteristics of the fabricated solar cells have been studied. 


\section{EXPERIMENTAL DETAILS}

Titanium isopropoxide $\left.\mathrm{Ti}\left[\mathrm{OCH}\left(\mathrm{CH}_{3}\right)_{2}\right]_{4}, 97 \%\right)$, titanium butoxide (Ti $[\mathrm{O}$ $\left.\left.\left(\mathrm{CH}_{2}\right)_{3} \mathrm{CH}_{3}\right]_{4}, 97 \%\right)$, triethoxy ethyl silane, were purchased from Sigma -Aldrich and were used as received.

\subsection{Silane as Primer}

The FTO substrates were ultrasonically cleaned in acetone, absolute ethanol and deionized water respectively for $15 \mathrm{~min}$ and finally dried. A solution of ethanol and water is prepared and the $\mathrm{pH}$ is adjusted to lie within 4.5-5.5 by using acetic acid. Triethoxy ethyl silane is added and the solution is stirred for half an hour. FTO substrates are dipped into the solution, agitated gently, and removed after 1 - 2 minutes. They are rinsed in ethanol. Curing of silane is achieved by keeping the layer for $5-10$ minutes at $110^{\circ} \mathrm{C}$.

After the pretreatment of the FTO substrate with triethoxy ethyl silane, the synthesis of $\mathrm{TiO}_{2}$ nanorods by hydrothermal method, extraction of natural dyes from flowers of Sesbania grandiflora, leaves of Camellia sinensis and roots of Rubia tinctorum, sensitization of $\mathrm{TiO}_{2}$ films with extracted natural dyes and fabrication of the sensitized $\mathrm{TiO}_{2}$ electrode based DSSC has been carried out as reported by Yuvapragasam et al., 2015 [9].

\subsection{The characterization}

The structural properties of the prepared samples have been studied using X-ray diffractometer (RigakuRint 2000 series). The surface morphology was studied using fieldemission scanning electron microscope (FE-SEM, ZEISS, SIGMA, UK). The high-resolution transmission electron microscope images of the films have been recorded using a JEOL, JEM2100 microscope. The thickness of the film was measured using surface profileometer= The absorbance spectra of the films have been recorded using spectrophotometer (Jasco V-570). The I - V curves of DSSCs were obtained using a Keithley 2400 digital source meter under an irradiation of $100 \mathrm{~mW} / \mathrm{cm}^{2}$. 


\section{Results and discussion}

\subsection{Necessity of a coupling agent:}

The $\mathrm{pH}$ of the precursor solution used in this experiment, for the synthesis of $\mathrm{TiO}_{2}$ nanorods was less than 3 due to the high $\mathrm{HCl}$ concentration which is favorable for the growth of $\mathrm{TiO}_{2}$ nanorods. At low $\mathrm{pH}(<3) \mathrm{TiO}_{2}$ particles are likely to be protonated. The similarly charged particles therefore repel each other and agglomeration does not occur.This leads to peeling of the film, when the reaction reached equilibrium. Hence there is a necessity of a coupling agent for the binding of the film with the substrate and at the same time the coupling agent should be nontoxic, volatile and should not take part in the chemical reaction involved during the synthesis of $\mathrm{TiO}_{2}$ films. Silanes come as the best coupler since silanes have high volatility that causes much of the silane material to evaporate before the chemical reaction forms the silicon resins. This evaporation causes a high silane concentration, as much as $40 \%$, to be lost through evaporation.

Commercially available silane based precursor molecules are mostly functionalized with trichlorosilane, trimethoxysilane or triethoxysilane groups, which react with the surface to form a covalent network. In this respect the trichlorosilane is the most reactive precursor, while trimethoxy- and triethoxysilanes are less reactive. In choosing a silane as a primer, the introduced functional groups should not interact with the surface and/or should not react with the silane groups to avoid the formation of multilayers or the destruction of the silane groups, respectively. These molecules will react with atmospheric moisture or water adsorbed on a surface to form silanols. These silanols can then react with other silanols to form a stable siloxane bond (-Si-O-Si-). In the presence of hydroxyl groups at the surface of glass, minerals or metals (e.g., aluminum, steel), silanols will form a stable $\mathrm{M}-\mathrm{O}-\mathrm{Si}$ bond ( $\mathrm{M}=\mathrm{Si}, \mathrm{Al}, \mathrm{Fe}$, etc.) [10].This is the key chemistry that allows silanes to function as valuable surface-treating or "coupling" agent.

\subsection{Structural analysis}

The FESEM images of the preparedTiO $\mathrm{T}_{2}$ thin films are shown in Fig. 4. It is evident from Fig. 4 that the films are made up of densely packed $\mathrm{TiO}_{2}$ nanorods. The average

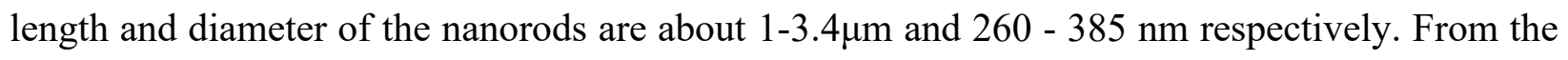
top view of FESEM images in Fig. 4(a) it can be observed that the $\mathrm{TiO}_{2}$ nanorods are grouped and look similar to a flower bouquet. The assemblies of nanorods in the form of bouquets have a 
diameter in the range $8.4-9.4 \mu \mathrm{m}$. In the present work, triethoxy ethyl silane acts as primer in substrate modification and helps in achieving highly packed $\mathrm{TiO}_{2}$ nanorods arranged in the form of bouquet.

The $\mathrm{HCl}$ used plays an important role in the hydrolysis rate of Ti by providing an acidic environment. When the concentration of $\mathrm{HCl}$ increases, the growth rate of $\mathrm{TiO}_{2}$ nanorods becomes faster and thus a large number of clusters form in the solution by homogeneous nucleation and acts as nucleating centres for further growth of nanorods. Since there is no crystal plane for these clusters, nanorods grow along any direction and then self assemble into a flower bouquet. The top - view SEM image of $\mathrm{TiO}_{2}$ nanorods shows that every single nanorod is etched into smaller nano wires while all of the original nanorods keep the uniform outline which is clear from the TEM images (Fig.5a). Hence the etching rate changes the size of the bunched $\mathrm{TiO}_{2}$ nanorods. Wenxi Guo et al. [11] suggested that the surface area of bunched nanorods is larger than that of unetched nanorods which enables more adsorption of dye molecules.
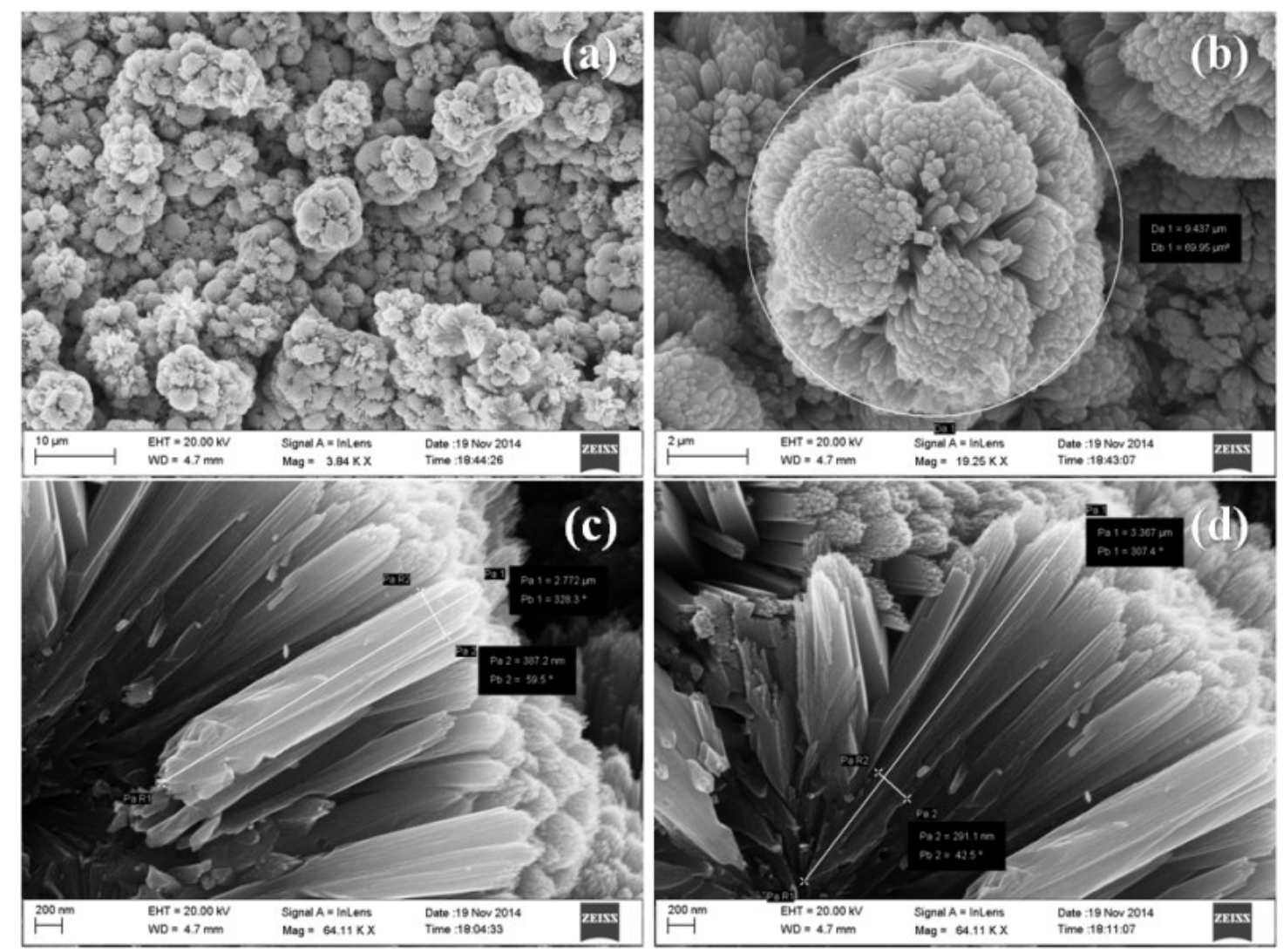

Fig.4 FESEM images of $\mathrm{TiO}_{2}$ nanorods synthesized using Triethoxy ethyl silane as primer 

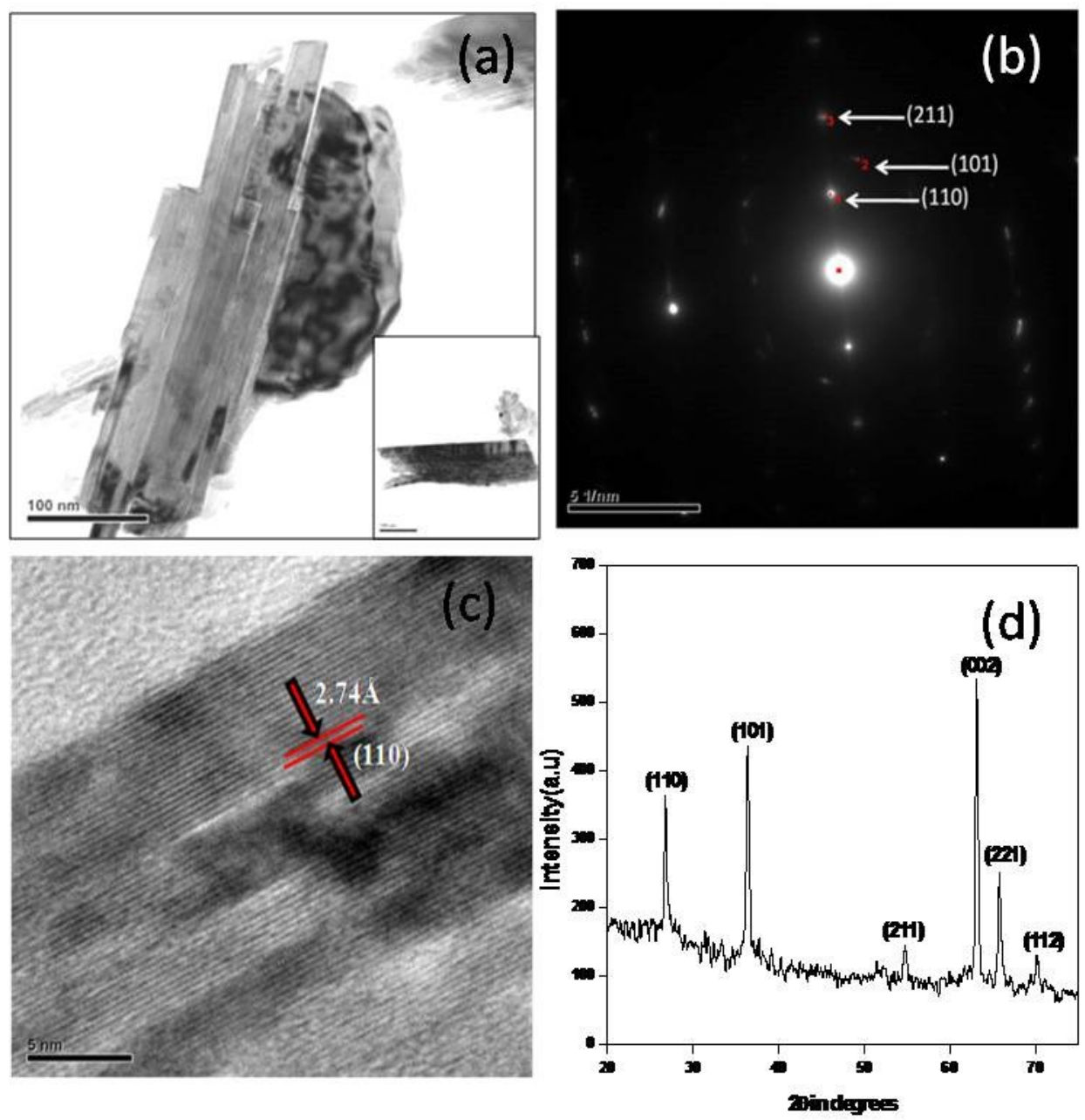

Fig.5. (a) TEM images of $\mathrm{TiO}_{2}$ nanorods grown by hydrothermal method (b) SAED pattern of $\mathrm{TiO}_{2}$ nanorods (c) HRTEM images of $\mathrm{TiO}_{2}$ nanorods grown by hydrothermal method (d) X-ray diffraction pattern of the prepared $\mathrm{TiO}_{2}$ sample.

The TEM images of the $\mathrm{TiO}_{2}$ nanorods are shown in Fig. 5(a). The inset image shows that each rod is made up of bunch of rods in the form of clusters which are closely packed and appears as a single rod. The presence and distribution of spots in SAED image (Fig. 5b) clearly shows that the aligned nanorods are single crystalline $\mathrm{TiO}_{2}$ with rutile structure. This has been confirmed with XRD and HRTEM characterizations.

The lattice fringes in Fig. 5c exhibit a lattice d-spacing of $2.47 \AA$ which corresponds to the (110) plane of rutile $\mathrm{TiO}_{2}$. The rutile phase has been further confirmed via $\mathrm{XRD}$ (Fig.5d). The peaks are at $27.36^{\circ}, 36.1^{\circ}, 54.31^{\circ}, 62.80^{\circ}, 65.90^{\circ}$ and $70.08^{\circ}$ corresponding to 
(110),(101),(211),(002),(221) and (112) planes of rutile phase. From the XRD profile it is clear that the main peak is (002) peak. No peaks corresponding to anatase or brookite phase is observed in the diffraction pattern.

Generally a nanostructured film with high nanorod density results in reduced effective surface area and thus weak dye adsorption [12]. So in the present study potash alum was used as a mordant to enhance the dye adsorption over nanorods electrodes. Mordants are metal cations which act as a bridge between dye molecules and substrate. The mordant links to specific functional groups of the dye molecule by covalent and coordination bonds and the pigments are precipitated as in-soluble metal dye complexes in alkaline solution [13]. Alum and ferrous sulphate are considered as the safest among metallic salt mordants [14,15]. The $\mathrm{TiO}_{2}$ films were immersed in the mordant solution for one hour. The mordant treated $\mathrm{TiO}_{2}$ electrodes were sensitized using the dye extracts from flowers of Sesbania grandiflora, leaves of Camellia sinensis and roots of Rubia tinctorum. The $\mathrm{TiO}_{2}$ electrodes were immersed in the dye solution in the dark for 6 hrs. The dye molecules are adsorbed into the $\mathrm{TiO}_{2}$ film which is clearly observed by the color change of the electrode.

\subsection{Sensitization of $\mathrm{TiO}_{2}$ thin films}
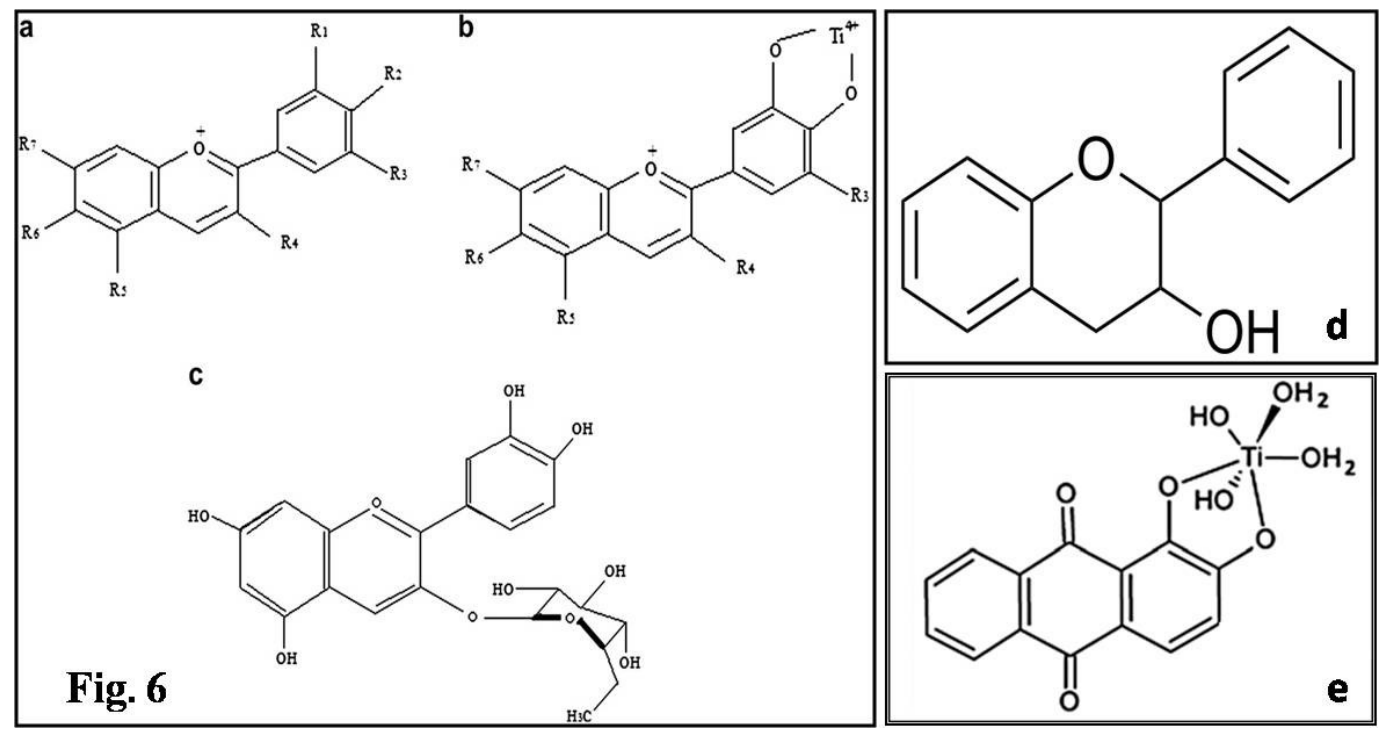

Fig.6.(a) Basic chemical structure of the anthocyanidins, (b) hydroxyl groups present in the anthocyanidins chelating with $\mathrm{TiO}_{2}$, (c) structure of the cyanidin 3-O-glucoside, (d) Structure of Flavan - 3-ol, (e) chelation of alizarin with $\mathrm{TiO}_{2}$ 
The natural dye extracts from the flowers Sesbania grandiflora, leaves of Camellia sinensis come under anthocyanins (Fig.3). Anthocyanins are flavonoids whose major function is to provide colors to most flowers and fruits. The most common anthocyanidins Fig. 6(a) found in flowers and fruits are cyanidin (orange-red), delphinidin (blue-red), malvidin (bluered) pelargonidin (orange), peonidin (orange-red) and petunidin (blue-red) [16,17]. The hydroxyl groups present in anthocyanidins chelating with $\mathrm{TiO}_{2}$ is shown in Fig. 6(b). Sesbania grandiflora used in the present study is having anthocyanin as cyanidin 3-O-glucoside [18]. The structure of the cyanidin 3-O-glucoside is shown in the Fig. 6(c). The carbonyl and hydroxyl groups present in the anthocyanin molecule can attach itself to the surface of a porous $\mathrm{TiO}_{2}$ film. This helps in electron transfer from the anthocyanin molecule to the conduction band of $\mathrm{TiO}_{2}$.

Leaves of Camellia sinensis contains very large amount of polyphenols, which is the most specific feature of tea. The main flavonoids found in tea are flavan- 3-ols, accounting for more than $90 \%$ of the total flavonoid content in tea, the remaining flavonoids are flavonols [2]. The structure of Flavan -3 -ol is shown in Fig.6 (d).

Alizarin naturally occurs in the roots of the madder plant (Rubia tinctorum). The alizarin pigments in the roots of Rubia tinctorum are the derivatives of anthraquinone (Fig.1). Anthraquinones are the largest group of naturally occurring quinones. Both natural and synthetic anthraquinones have been widely used as colorants in various fields. Chelation of alizarin with $\mathrm{TiO}_{2}$ is shown in Fig.6 (e). The alizarin dyes are based on three six-membered carbon rings, the central quinone ring and two peripheral ones with two hydroxyls in various positions. All these molecules are coplanar and of similar bond lengths. The quinone moiety in dihydroxy anthraquinones serves as an electron acceptor, while the phenolic groups are electron donors. This is substantiated by a significant asymmetry in charge distribution within studied molecules. These moieties are arranged in different configurations within molecules which is in turn responsible for specific properties of dihydroxy anthraquinone dyes and may be especially important for their respective photoelectrochemical behavior at the surface of wide band gap semiconductors, e.g. $\mathrm{TiO}_{2}[19]$. 

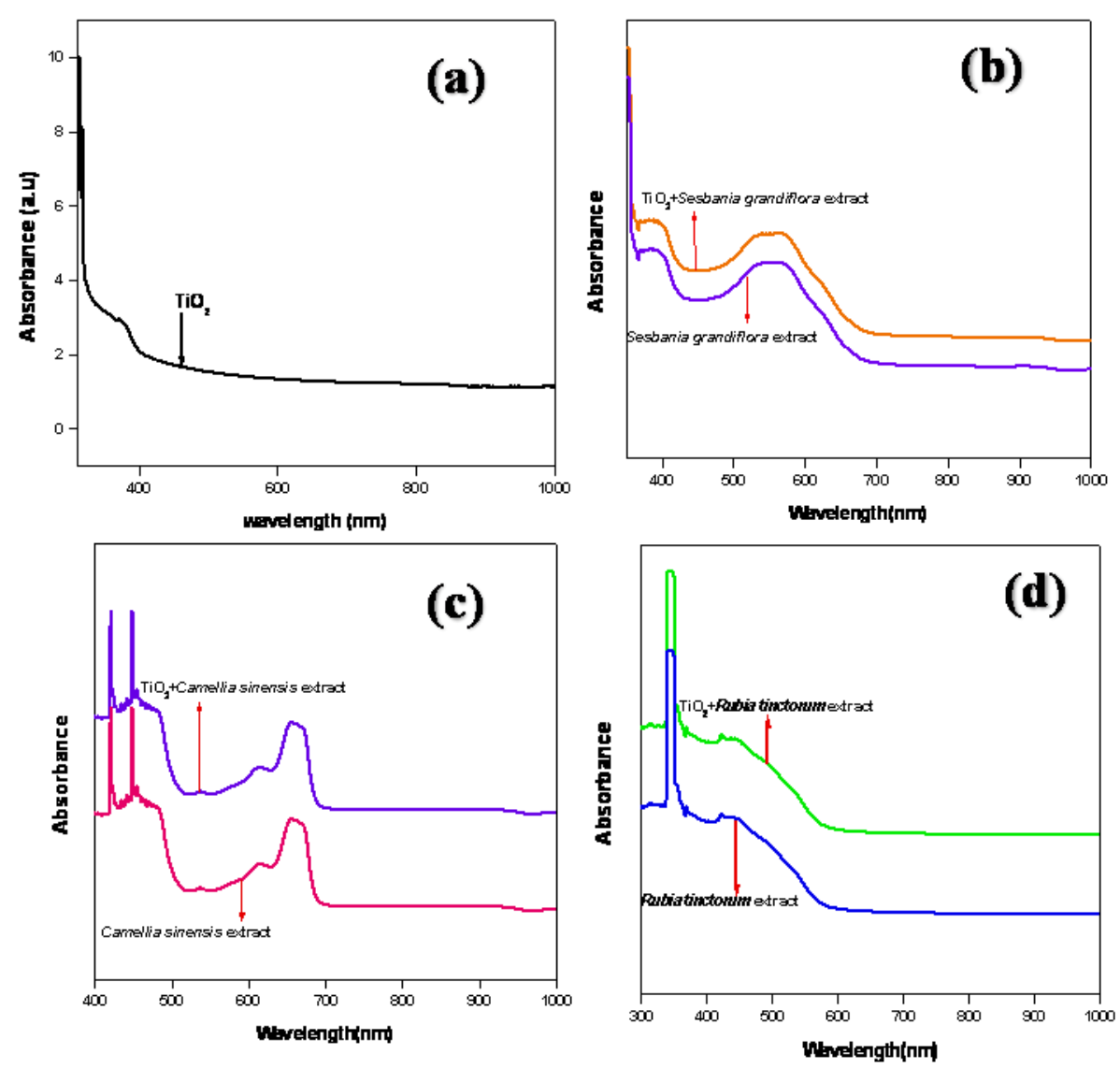

Fig. 7. Absorption spectra of (a) $\mathrm{TiO}_{2}$ film (b) extract of flowers of Sesbania grandiflora and $\mathrm{TiO}_{2}$ film sensitized by Sesbania grandiflora extract (c) extract of leaves of Camellia sinensis and $\mathrm{TiO}_{2}$ film sensitized by Camellia sinensis extract (d) extract of roots of $\mathrm{Rubia}$ tinctorum and $\mathrm{TiO}_{2}$ film sensitized by Rubia tinctorum extract.

Fig. 7 shows the absorption spectra of (a) the $\mathrm{TiO}_{2}$ film (b) extract of flowers of Sesbania grandiflora and $\mathrm{TiO}_{2}$ film sensitized by Sesbania grandiflora extract (c) extract of leaves of Camellia sinensis and $\mathrm{TiO}_{2}$ film sensitized by Camellia sinensis extract (d) extract of roots of Rubia tinctorum and $\mathrm{TiO}_{2}$ film sensitized by Rubia tinctorum extract. From Fig. 4 (b), (c), (d) it can be observed that the absorbance of dye sensitized $\mathrm{TiO}_{2}$ film shows an increase in the absorbance due to dye sensitization.

Sesbania grandiflora anthocyanins are mostly in the form of glycosides and they have sugar molecules chemically attached to them. Some have acyl functional groups or have acyl functional group in combination with sugar molecules. If the acyl group is attached to an - 
$\mathrm{OH}$ group, it would form an ester linkage. The acyl groups can contribute greatly to color stability. It is generally accepted that the chemical adsorption of the dye takes place due to condensation of alcoholic - bound protons with the hydroxyl groups in the surface of nanostructured $\mathrm{TiO}_{2}$ (Fig .6(c)) . Therefore, this chemical attachment affects the energy levels of the highest occupied molecular level (HOMO) and the lowest unoccupied molecular level (LUMO) of these pigments which eventually affects the band gap of these materials [16].

The main flavonoids found in tea are flavan- 3-ols, accounting for more than $90 \%$ of the total flavonoid content in tea, the remaining flavonoids are flavonols [20]. The intensity of light absorption has been enhanced due to the interfacial $\mathrm{Ti}-\mathrm{O}$ coupling which exists between the $\mathrm{C}=\mathrm{O}, \mathrm{C}-\mathrm{H}, \mathrm{C}-\mathrm{O}, \mathrm{O}-\mathrm{H}$ bonding of dye molecules and $\mathrm{TiO}_{2}$ molecules [21]. Flavonoids are good chelating agents towards metal ions and, in the case of iron and copper, the favoured places of chelation are catechol groups, hydroxyl groups adjacent to oxo groups, and 1-oxo-3-hydroxylcontaining moieties $[22,23]$. This ability to chelate metals has been used to assist the elucidation of flavonoid glucuronides [24, 25] and various diglycosides [26]. This is a result of the spectral changes observed when flavonoids are complexed with metals, giving rise to simpler yet more intense spectra [27].

Alizarin naturally occurs in the roots of the madder plant (Rubia tinctorum). Alizarin is a good photo sensitizer and arouses great interest as a modifier in dye sensitized solar cells. Adsorption of turmeric, madder and alkanet to the semiconductor $\mathrm{TiO}_{2}$ surface is a quick reaction, forming a very strong complex showing prevalently the quinonodial form [28]. This chemical reaction is the result of alcoholic bound protons which condense with the hydroxyl groups present at the surface of nanostructured $\mathrm{TiO}_{2}$ film with the contribution of the chelating

effect due to the two nearest hydroxyl groups towards Ti (IV) sites on the semiconductor nanocrystalline layer [29]. The anthraquinone family offers a wide range of excited state properties that can modulate the photoelectrochemistry of a hybrid system with preserved (in most cases) photosensitizer-semiconductor binding mode [19].

\subsection{Performance of dye sensitized solar cells}

Fig. 8 shows the $\mathrm{J}-\mathrm{V}$ characteristics of $\mathrm{TiO}_{2}$ based solar cells sensitized by natural dyes extracted from flowers of Sesbania grandiflora, leaves of Camellia sinensis and roots of Rubia tinctorum. The photo electrochemical activity is dependent on the morphology of 
the photo anode, therefore morphology control of $\mathrm{TiO}_{2}$ is supposed to be an effective way to improve the DSSCs performance [30].

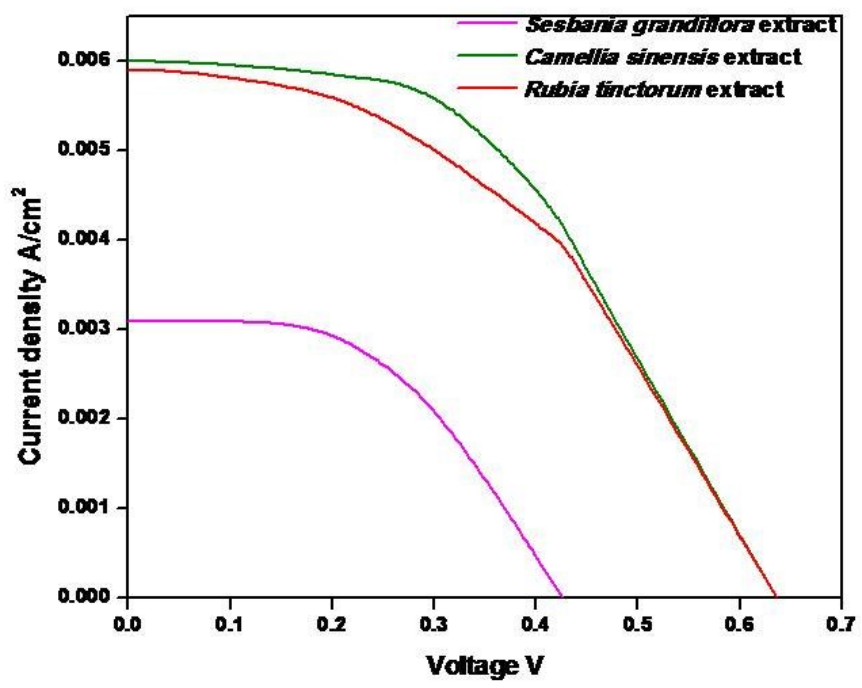

Fig. $8 \mathrm{~J}$ - $\mathrm{V}$ characteristics of $\mathrm{TiO}_{2}$ based solar cells sensitized by natural dyes extracted from flowers of Sesbania grandiflora, leaves of Camellia sinensis and roots of Rubia tinctorum.

Table 2 Solar cell parameters of the fabricated $\mathrm{TiO}_{2}$ based solar cells.

\begin{tabular}{|l|c|c|c|c|}
\hline $\begin{array}{l}\text { Dye extract / Solar } \\
\text { cell parameters }\end{array}$ & Voc(V) & JSC $\left(\mathbf{m A} / \mathbf{c m}^{2}\right)$ & FF(\%) & Efficiency (\%) \\
\hline Sesbaniagrandiflora & 0.426 & 3.1 & 49.2 & 0.65 \\
\hline Camellia sinensis & 0.636 & 6.0 & 40.09 & 1.53 \\
\hline Rubiatinctorum & 0.636 & 5.9 & 34.17 & 1.28 \\
\hline
\end{tabular}

The solar cell fabricated using $\mathrm{TiO}_{2}$ sensitized with the flowers of Sesbania grandiflora dye extract exhibited a power conversion efficiency of $0.65 \%$ with a short circuit current density (Jsc) of $3.1 \mathrm{~mA} / \mathrm{cm}^{2}$, open circuit voltage (Voc) of $0.426 \mathrm{~V}$ and fill factor (FF) of $49.2 \%$. The power conversion efficiency exhibited by the solar cell fabricated using $\mathrm{TiO}_{2}$ sensitized by leaves of Camellia sinensis and roots of Rubia tinctorum are have been $1.53 \%$ and $1.28 \%$ respectively. The solar cell parameters of the fabricated natural dye sensitized solar cells are given in Table 2. The short circuit current density, fill factor, open circuit voltage and the 
efficiency obtained by the $\mathrm{TiO}_{2}$ based solar cell sensitized by leaves of Camellia sinensis were found to be $6.0 \mathrm{~mA} / \mathrm{cm}^{2}, 40.09 \%, 0.636 \mathrm{~V}$ and $1.53 \%$ respectively. The efficiency obtained by the $\mathrm{TiO}_{2}$ based solar cell sensitized by roots of Rubia tinctorum is $1.28 \%$ with a short circuit current density of $5.9 \mathrm{~mA} / \mathrm{cm}^{2}$ and fill factor of $34.17 \%$. The efficiency obtained by Tadesseet al., 2012 [31] for Syzygium guineense was 0.51\%. Earlier Sönmezoğluet. al., 2012 [32] reported an efficiency of $1.7 \%$ for alizarin pigment obtained from Rubia tinctorum along with ferrocenebased electrolyte.

Calogero et al. suggested that "Finding appropriate additives for improving open circuit voltage VOC without causing dye degradation might result in a further enhancement of cell performance, making the practical application of such systems more suitable to economically viable solar energy devices for our society[33].” The better extraction of dyes with further sensitization of the $\mathrm{TiO}_{2}$ film for improving $V_{\mathrm{OC}}$ and $\mathrm{Jsc}$ may result in further enhancement of cell performance, making the practical application of such systems more suitable for achieving economically viable solar energy devices.

\section{Conclusion}

Rutile $\mathrm{TiO}_{2}$ nanorods were synthesized by hydrothermal method using triethoxy ethyl silane as primer. FESEM images show the acropora coral like arrangement of $\mathrm{TiO}_{2}$ nanorods. XRD pattern shows the formation of rutile phase $\mathrm{TiO}_{2}$. Dyes obtained from flowers of three different plants were used as sensitizers in DSSCs. The dyes extracted from these materials contained anthocyanins, flavanols and alizarin. The photoelectrochemical performance of the DSSCs based on these dyes showed a $\mathrm{V}_{\mathrm{OC}}$ ranging from 0.43-0.64 V, and $\mathrm{J}_{\mathrm{SC}}$ was in the range of 3.1-6 mA cm${ }^{-2}$. The DSSC sensitized by leaves of Camellia sinensis pigment offered the highest conversion efficiency of $1.53 \%$ among the extracts. This is due to the better charge transfer between the leaves of Camellia sinensis dye molecule and the $\mathrm{TiO}_{2}$ surface, which is related to a dye structure.

\section{REFERENCES}

01. Gratzel, M.; J. Photochem. Photobiol., C 2003, 4, 145.

02. Tennakone, K.; Kumara, G. R. R. R. A.; Kumarasinghe, A. R.; Sirimanne, P. M.; Wijayantha, K. G. U.; J. Photochem. Photobiol., A 1996, 94, 217. 
03. Plant Seeds-Based Dye-Sensitized Solar Cells, Monzir S. Abdel-Latif, Taher M. ElAgez, Sofyan A. Taya, Amal Y. Batniji , Hatem S. El-Ghamri, Materials Sciences and Applications, 2013, 4, 516-520

04. Wang, X.-F., Zhan, C.-H., Maoka, T., Wada, Y. \& Koyama, Y. 2007. Fabrication of dye-sensitized solar cells using chlorophylls c 1 and c 2 and their oxidized forms and from Undaria pinnatifida (Wakame). Chemical physics letters, 447, 79-85.

05. Kay, A. \& Graetzel, M. 1993. Artificial photosynthesis. 1. Photosensitization of titania solar cells with chlorophyll derivatives and related natural porphyrins. The Journal of Physical Chemistry, 97, 6272-6277.

06. Wang, X.-F., Fujii, R., Ito, S., Koyama, Y., Yamano, Y., Ito, M., Kitamura, T. \& Yanagida, S. 2005. Dye-sensitized solar cells using retinoic acid and carotenoic acids: Dependence of performance on the conjugation length and the dye concentration. Chemical physics letters, 416, 1-6.

07. Kumara, N., Ekanayake, P., Lim, A., Liew, L. Y. C., Iskandar, M., Ming, L. C. \& Senadeera, G. 2013. Layered co-sensitization for enhancement of conversion efficiency of natural dye sensitized solar cells. Journal of Alloys and Compounds, 581, 186-191.

08. Zaman, A. C., Üstündağ, C. B., Kaya, F. \& Kaya, C. 2012. Synthesis and electrophoretic deposition of hydrothermally synthesized multilayer TiO 2 nanotubes on conductive filters. Materials Letters, 66, 179-181.

09. Yuvapragasam, A., Muthukumarasamy, N., Agilan, S., Velauthapillai, D., Senthil, T. \& Sundaram, S. 2015. Natural dye sensitized $\mathrm{TiO}_{2}$ nanorods assembly of broccoli shape based solar cells. Journal of Photochemistry and Photobiology B: Biology, 148, $223-$ 231.

10. Materne, T., De Buyl, F. \& Witucki, G. L. 2012. Organosilane technology in coating applications: Review and perspectives. Dow Corning Corporation., AGP11933, Form No.

11. Guo, W., Xu, C., Wang, X., Wang, S., Pan, C., Lin, C., \& Wang, Z. L. (2012). Rectangular bunched rutile $\mathrm{TiO}_{2}$ nanorod arrays grown on carbon fiber for dyesensitized solar cells. Journal of the American Chemical Society, 134(9), 4437-4441. 
12. Pottier, A., Chanéac, C., Tronc, E., Mazerolles, L. \& Jolivet, J.-P. 2001. Synthesis of brookite $\mathrm{TiO} 2$ nanoparticlesby thermolysis of $\mathrm{TiCl} 4$ in strongly acidic aqueous media. $J$. Mater. Chem., 11, 1116-1121.

13. Clementi, C., Doherty, B., Gentili, P., Miliani, C., Romani, A., Brunetti, B. \& Sgamellotti, A. 2008. Vibrational and electronic properties of painting lakes. Applied Physics A, 92, 25-33.

14. Savvidis, G., Zarkogianni, M., Karanikas, E., Lazaridis, N., Nikolaidis, N. \& Tsatsaroni, E. 2013. Digital and conventional printing and dyeing with the natural dye annatto: optimisation and standardisation processes to meet future demands. Coloration Technology, 129, 55-63.

15. Zarkogianni, M., Mikropoulou, E., Varella, E. \& Tsatsaroni, E. 2011. Colour and fastness of natural dyes: revival of traditional dyeing techniques. Coloration Technology, 127, $18-27$.

16. Fernando, J. \& Senadeera, G. 2008. Natural anthocyanins as photosensitizers for dyesensitized solar devices. Curr. Sci, 95, 10.

17. Sakata, K., Saito, N. \& Honda, T. 2006. Ab initio study of molecular structures and excited states in anthocyanidins. Tetrahedron, 62, 3721-3731.

18. Nielsen, A. H., Olsen, C. E. \& Møller, B. L. 2005. Flavonoids in flowers of 16 Kalanchoe blossfeldiana varieties. Phytochemistry, 66, 2829-2835.

19. Mech, J., Grela, M. A. \& Szaciłowski, K. 2014. Ground and excited state properties of alizarin and its isomers. Dyes and Pigments, 103, 202-213.

20. Bell. J. P., Schmidt. R. G., Malofsky A., Mancini D., 1992. Silanes and Other Coupling Agents. K. L. Mittal (Ed.). VSP, Utrecht. 49-66.

21. WU, S. 1982. Polymer interface and adhesion, M. Dekker.

22. Ren, J., Meng, S., Lekka, C. E. \& Kaxiras, E. 2008. Complexation of Flavonoids with Iron: structure and optical signatures. The Journal of Physical Chemistry B, 112, 18451850.

23. Fernandez, M. T., Mira, M. L., Florencio, M. H. \& Jennings, K. R. 2002. Iron and copper chelation by flavonoids: an electrospray mass spectrometry study. Journal of Inorganic Biochemistry, 92, 105-111. 
24. Davis, B. D., Needs, P. W., Kroon, P. A. \& Brodbelt, J. S. 2006. Identification of isomeric flavonoid glucuronides in urine and plasma by metal complexation and LC-ESI-MS/MS. Journal of mass spectrometry, 41, 911-920.

25. Davis, B. D. \& Brodbelt, J. S. 2008. Regioselectivity of human UDP-glucuronosyltransferase $1 \mathrm{~A} 1$ in the synthesis of flavonoid glucuronides determined by metal complexation and tandem mass spectrometry. Journal of the American Society for Mass Spectrometry, 19, 246-256.

26. Pikulski, M., Aguilar, A. \& Brodbelt, J. S. 2007. Tunable transition metal-ligand complexation for enhanced elucidation of flavonoid diglycosides by electrospray ionization mass spectrometry. Journal of the American Society for Mass Spectrometry, $18,422-431$.

27. Satterfield, M. \& Brodbelt, J. S. 2000. Enhanced detection of flavonoids by metal complexation and electrospray ionization mass spectrometry. Analytical chemistry, 72, 5898-5906.

28. Duncan, W. R. \& Prezhdo, O. V. 2005. Nonadiabatic molecular dynamics study of electron transfer from alizarin to the hydrated Ti4+ ion. The Journal of Physical Chemistry B, 109, 17998-18002

29. Moustafa, K., Rekaby, M., El Shenawy, E. \& Khattab, N. 2012. Green dyes as photosensitizers for dyesensitized solar cells. Journal of Applied Sciences Research, 8, 4393-4404.

30. Mali, S., Desai, S., Dalavi, D., Betty, C., Bhosale, P. \& Patil, P. 2011. CdS-sensitized $\mathrm{TiO}_{2}$ nanocorals: hydrothermal synthesis, characterization, application. Photochemical \& Photobiological Sciences, 10, 1652-1658.

31. Tadesse, S., Abebe, A., Chebude, Y., Garcia, I. V. \& Yohannes, T. 2012. Natural dyesensitized solar cells using pigments extracted from Syzygium guineense. Journal of Photonics for Energy, 2, 027001-1-027001-10.

32. Sönmezoğlu, S., Akyürek, C. \& Akin, S. 2012. High-efficiency dye-sensitized solar cells using ferrocene-based electrolytes and natural photosensitizers. Journal of Physics D: Applied Physics, 45, 425101. 
33. Calogero, G., Di Marco,G., Caramori, S., Cazzanti, S., Roberto Argazzi, R. and Bignozzi, C.A. 2009. Natural dye senstizers for photoelectrochemical cells. Energy Environ. Sci., Vol. 2, Issue 11, pp. 1162-1172. 